Classification

Physics Abstracts

$81.40-07.80-81.30 \mathrm{M}$

\title{
First attempt towards the direct determination of the Guinier- Preston zones (GP1) copper content in Al-1.7 at \% Cu alloy
}

\author{
Bernard Jouffrey and Miroslav Karlík \\ Ecole Centrale Paris, LMSS-Mat, Grande Voie des Vignes, 92295 Châtenay-Malabry, France
}

(Received June 26, 1992; accepted July 28, 1992)

\begin{abstract}
Résumé . - A la suite de travaux récents qui confirment que nombre de zones Guinier-Preston (GP1) dans l'alliage $\mathrm{Al}-1,7 \%$ at. $\mathrm{Cu}$ sont des monocouches atomiques riches en cuivre, les auteurs ont essayé de déterminer directement la concentration en cuivre dans les zones. Des résultats préliminaires obtenus avec de nouveaux microscopes électroniques à transmission équipés d'un canon à émission de champ (FEG), donnent une concentration en cuivre égale à $50 \%$ ou moins. L'influence du faisceau sur une possible évolution des zones est discutée. Les chocs directs électrons-noyaux des atomes d'aluminium représentent les interactions qui peuvent endommager le plus l'échantillon. Cet effet est génant surtout en analyse qui nécessite de fortes doses locales d'électrons primaires. Il est donc preférable d'utiliser, ce qui est effectivement possible, la microscopie électronique sous le seuil de formation des défauts.
\end{abstract}

\begin{abstract}
Starting from recent results on the observation of atomic monolayers Guinier-Preston zones (GP1) in Al-1.7 at\% Cu alloy, by means of atomic resolution in transmission electron microscopy, the authors try to detect directly the concentration of $\mathrm{Cu}$ in GP1 zones. Preliminary results, obtained with transmission electron microscopes equipped with a field emission gun (FEG), are presented. They give a content of copper of the order of $50 \%$ or less. The problem of damaging the crystalline ordering of the zones under the beam is discussed. Above the displacement threshold, direct knock-on of electrons with aluminium nucleus is the major damaging interaction. This effect is more important for the direct determination of the copper concentration in the zones by means of EELS or X-ray elemental analysis. It is concluded that sub-threshold electron microscopy has to be preferably used.
\end{abstract}

\section{Introduction.}

The question of Guinier-Preston (GP) zones in $\mathrm{Al}-1.7 \mathrm{at} \% \mathrm{Cu}$ is considered as an historical major problem in metallurgy of light alloys. The presence of these zones explains the hardening of these alloys following quenching from a temperature close to the melting point and subsequent annealing at room temperature, or say $100^{\circ} \mathrm{C}$, as an order of magnitude, during several hours.

As it is well known, the GP zones structure and formation is a more general problem that the one concerning aluminium-copper alloys only (the zones appear also in $\mathrm{Al}-\mathrm{Zn}, \mathrm{Cu}-\mathrm{Be}, \mathrm{Fe}-\mathrm{Mo}, \mathrm{Al}-$ $\mathrm{Ag} \mathrm{etc}$ ), even if $\mathrm{Al}-1.7$ at.\% $\mathrm{Cu}$ alloy, a composition which is slightly below the limit of solubility, has been the most extensively studied. The zones are planar and formed in $\{100\}$ planes (in Al$\mathrm{Ag}$ they are spherical). A majority of them appear as monolayers which are rich in copper, the 
atoms of which being substitutional. The local parameter, due to the presence of copper atoms, is slightly less $\left[\left(r_{\mathrm{Al}}-r_{\mathrm{Cu}}\right) / r_{\mathrm{Al}}=0.105\right]$ than the matrix aluminium parameter. The consequence is the appearance of a strain field around GP zones which gives hardening.

Three essential techniques have been used to understand the formation and the composition of these zones: X-ray diffraction, EXAFS and transmission electron microscopy. Since many years, it has been possible to detect that a strain-field does exist around GP zones and that it corresponds to a vacancy-like type as far as the sense of the deformation is concerned. That has been shown, in electron microscopy, by Ashby and Brown [1].

High resolution electron microscopy is now a useful tool to obtain new information on GP zones. Some studies have been carried out to observe directly GP zones at the atomic level. Most of them have used tilted illumination which is not quite recommended to extract precise information [2].

There are essentially four questions to be solved.

- What is the geometrical structure of the zones?

- What is the Cu content in the zones?

- What is the strain field around the zones?

- What is the mechanism to evolve from the solid solution to GP1 then to GP2 or $\theta^{\prime \prime}$ and $\theta^{\prime}$ ?

This paper essentially deals with the second point.

\section{Specimen preparation.}

The samples were prepared from high purity metals (Al5N, Cu4N5). The $0.15 \mathrm{~mm}$ thick strip was heated at $540^{\circ} \mathrm{C}$ for 1 hour and quenched in iced water and then annealed $100^{\circ} \mathrm{C}$ for 10 hours. Following this treatment, discs, $3 \mathrm{~mm}$ in diameter were stamped out from the foils. Electron microscopy thin foils were prepared by jet electro-polishing (TENUPOL) in E-2 Struers electrolyte at $-10^{\circ} \mathrm{C}$.

The final result is not completely reproducible. In particular, specimens often present a deposited layer which can produce troublesome contrasts. This layer can be removed by cleaning with a solution of nitric acid. It is also possible to use ion thinning as was used by Castaing [3, 4] in his early electron microscopy observations of GP zones. With this type of material, precautions have to be taken to avoid any heating of the sample under ion bombardment, which may cause a subsequent evolution of the alloy to further states of precipitation.

\section{Monolayers.}

High resolution electron microscopy, carried out with the Jeol 4000EX instrument in Grenoble (CENG) has been used to observe GP1 zones. Atomic columns were resolved in the GP1 zones, under the channeling zone axis orientation of the crystal which separates individual columns of atoms. Clearly, for our annealing conditions $\left(100^{\circ} \mathrm{C}\right.$ for ten hours), many of the studied GP zones were atomic monolayers as was early proposed by Guinier and Preston independently [5, 6].

It clearly appears by comparison with simulations that a number of zones extend from top to bottom of the sample, and can thus be easily studied. They appear more or less contrasted as a function of focus [7]. For a specific focus the contrast of zones can disappear completely and the contrast around this value of focus can be either black on a lighter background or the reverse.

Figure 1 shows a (100) [100] oriented area. It can be seen that GP zones appear either as a series of white dots (some of them are marked by arrows) or black streaks. Until now we have not unambiguously analysed the contrast of zones which appear as black streaks thicker than one 
atomic plane. However, we know from a previous study [2] that the series of white dots correspond to GP1 zones which are atomic monolayers rich in copper. This observation is obtained with the first negative oscillation of the transfer function. This condition gives an excellent contrast of atomic columns which appear brighter if they are rich in copper (Fig. 2). The contrast is due to the phase shift of the wave associated to incident electrons which is clearly different for the atomic columns very rich in $\mathrm{Cu}$ compared to the aluminium atomic columns. With these conditions it was recently shown that in some cases zones are not $100 \%$ rich in copper, when ordering is present [2]. However it is not still very clear what is, in general, the content of copper in the zones.

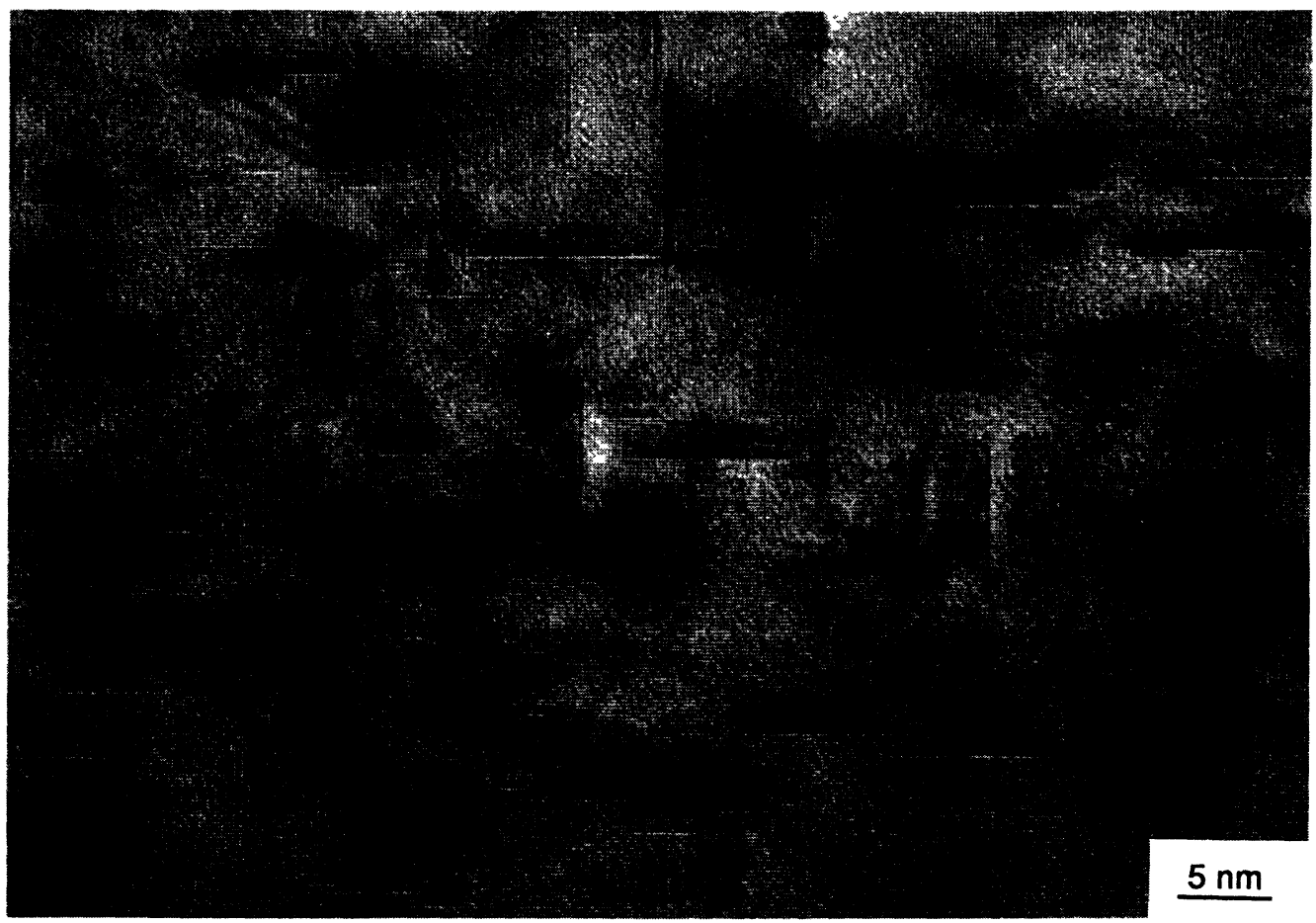

Fig. 1. - Atomic resolution micrograph in (100) [100] orientation. The monolayer GP1 zones appear as series of white dots (several of them are marked by the arrows) or black streaks ( $400 \mathrm{kV}$ Jeol electron microscope - CEN Grenoble).

It was attempted more than 10 years ago [8] to observe GP zones, using a symmetrical illumination. This first experiment was performed at $500 \mathrm{kV}$ with the HAREM apparatus in Kyoto. From simulations, it appeared that the zones we studied were composed of two copper-rich atomic planes. Deformation was included in the simulations. In our more recent experiments, the same kind of contrast is often observed. However, the interpretation of this last contrast is not still completely clear. It will be necessary to study other geometrical situations introducing the surface effect and the possibility of zones ending inside the sample.

On the other hand, zones observed in (100) [110] orientation are quite clearly monolayers as can be seen in figures 4 or 8 in reference [2]. We have observed, in a few cases, contrasts which can be interpreted as the very beginning of a transition towards two atomic layers. Figure 3 seems 


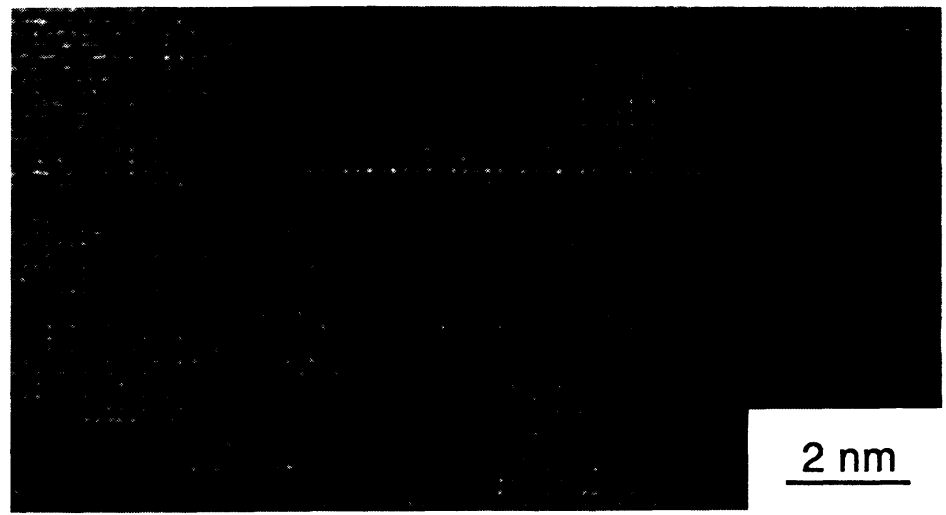

Fig. 2. - Detail of a monolayer zone in (100) [100] orientation (200 kV Hitachi HF-2000 electron microscope with field emission gun).

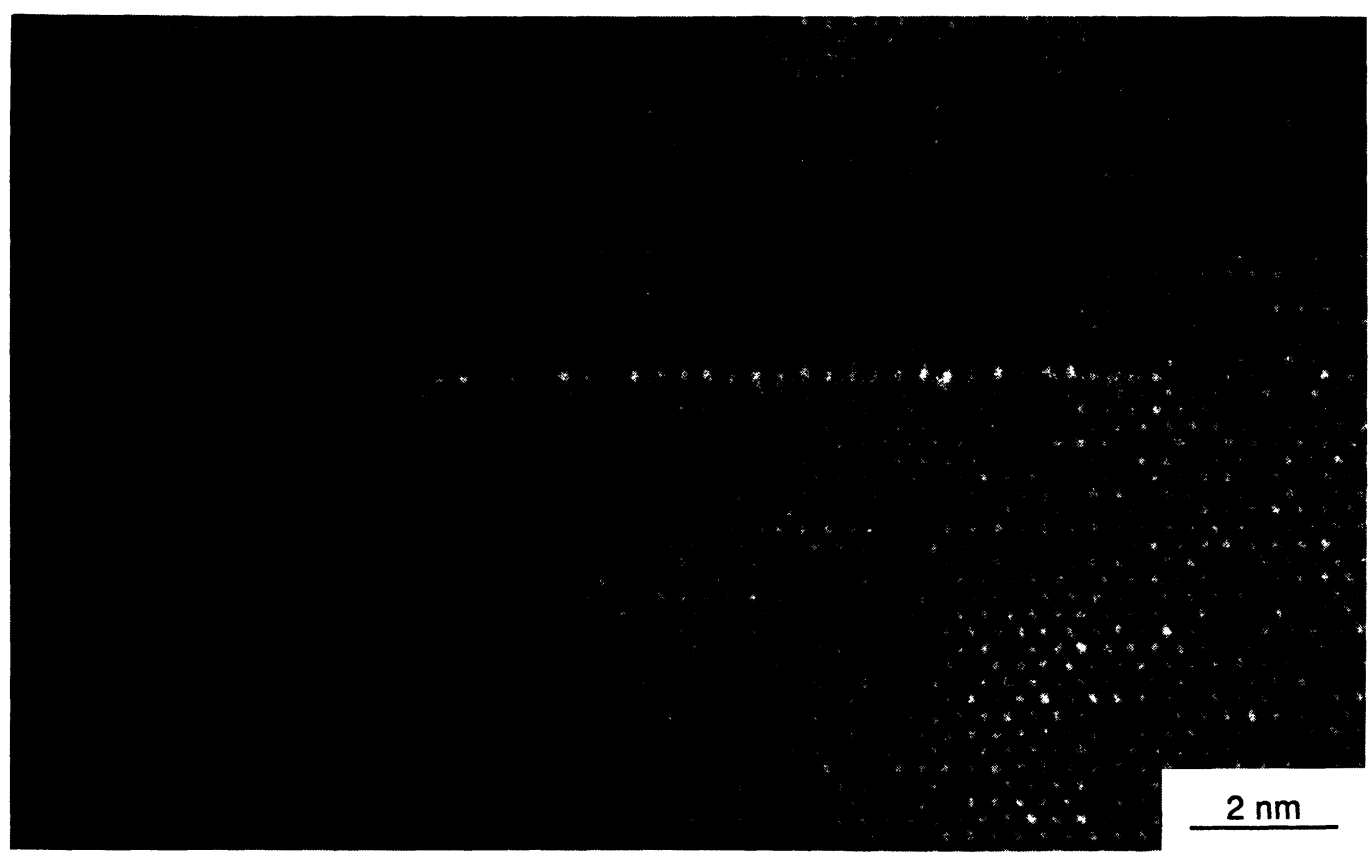

Fig. 3. - Detail of a monolayer zone in (100) [110] orientation. The zone is not any more a pure monolayer. It is to be noticed the connection of the zone with the adjacent atomic columns which are also rich in copper (400 kV Jeol electron microscope - CEN Grenoble).

a good example of this kind of evolution of a monolayer GP1 zone towards a more complicated structure.

The question is to know what are the best ways to determine the content of copper inside the zones. One way is to carry out high resolution electron microscopy. The comparison between experiments and computer simulations at the atomic level with different contents of substitutional 
copper atoms in the atomic columns, and different orientations, can be a reasonnable approach. We have begun to explore this approach in detail, but this specific part of the work is not still enough advanced to be mentionned more precisely here. However, it is clear that this approach has given us more precise ideas. Another way is to directly perform elemental analysis of copper by means of either characteristic X-rays or EELS. In fact both methods have to be followed and compared.

\section{Elemental analysis.}

The detection of characteristic photons or characteristic edges in the energy loss spectrum is not a real problem as far as the energies of $\mathrm{K}$ edges for $\mathrm{Al}$ and $\mathrm{L}$ edges for copper are concerned. The required sensitivity depends on the copper content in the zones but also on the geometry of the zones being either parallel or perpendicular to the beam. The most favourable situation for sensitivity in analysis would be to have the zone perpendicular to the beam. With this geometry, the sensivity depends on the thickness of the sample, and a single layer of copper embedded in a sample 50 atomic planes thick could be easily detected with a rather large beam, since the zones are about $10 \mathrm{~nm}$ in diameter. The necessary sensitivity of $2 \%$ is easily obtained. However, the difficulty is to be sure on the structure of the zones. Our observations show, for the present time, that stating positively a specific GP1 zone is a monolayer, is not always easy and demands to have first a specific orientation either (100) [100] or better (100) [110]. Therefore the elemental analysis has to be carried out using such an orientation, to observe first whether the zone is really a monolayer, and then determinate the concentration of atoms.

What is the right apparatus and convenient primary voltage to perform both analytical studies and atomic resolution on GP zones? The new generation of $200 \mathrm{kV}$ microscopes equipped with field emission guns (Hitachi, Philips) seems to be quite well designed to carry out this kind of observation. Beyond the first zero of the transfer function, the contrast becomes much higher than the one obtained with $\mathrm{a} \mathrm{LaB}_{6}$ gun. The gain in contrast, at this level is quite important and of the order of 16 . Therefore it is possible to take advantage of the capability of using the microscope beyond the first zero of the transfer function to observe the atomic columns of the GP1 zones in a channeling axis orientation. Figures 2 and 4 show examples of the observation at $200 \mathrm{kV}$ of GP1 zones as monolayers.

Consequently, the necessary resolution (better than $0.2 \mathrm{~nm}$ for an $\mathrm{Al}-\mathrm{Cu}$ alloy), can be obtained without difficulty with these modern electron microscopes. Another interest is the quality of the channelling conditions corresponding to the orientation we used ((100) [100] and (100) [110]). With FEG, due to the excellent possible parallelism of the beam, the penetration seems improved. In fact the contrast is better due to this quality of spatial coherency. More electrons penetrate the sample with the right channeling direction. In addition, as it is known, the temporal coherency is also very good. We refer to the papers of both companies for more details on the characteristics of these microscopes $[9,10]$.

As we mentioned above, the first need with GP zones is to be able to do high atomic resolution on a zone which is studied to confirm it is a monolayer and then to carry out an elemental analysis on the same zone.

4.1 X-ray ANALYSIS OF COPPER CONTENT. - We report different experiments which have been carried out to determine directly the atomic concentration of copper in the GP1 monolayers using both X-ray analysis.

Most of the experiments have been performed at $200 \mathrm{kV}$ with both most recent $200 \mathrm{kV}$ electron microscopes constructed by Hitachi (HF-2000) and Philips (CM20 Supertwin) equipped with a 


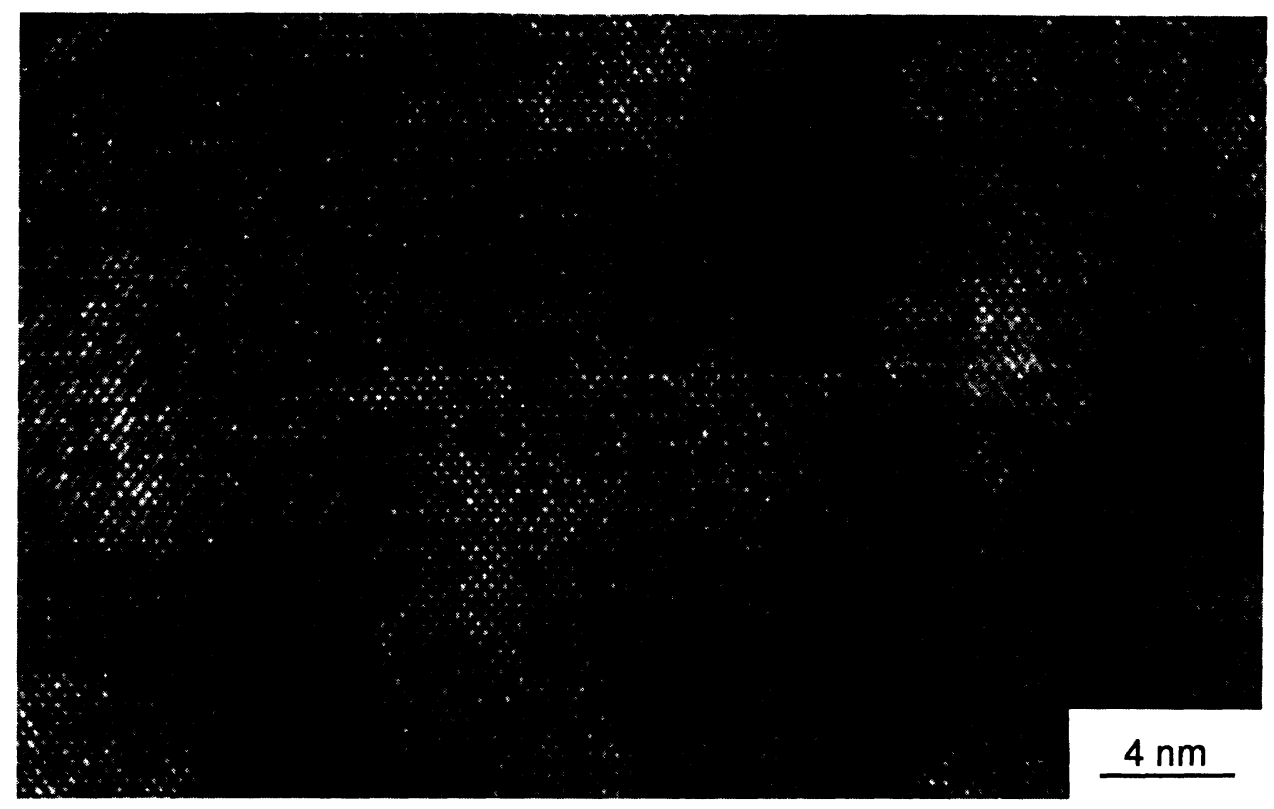

Fig. 4. - Detail of a monolayer zone in (100) [110] orientation - conditions close to the weakest contrast ( $200 \mathrm{kV}$ Philips CM20 Superwin electron microscope with field emission gun).

field emission gun $[9,10]$. We have chosen this accelerating voltage to obtain high resolution images and to detect an analytical signal which directly exhibits the change of concentration on and out of the zones. The analyses on both apparatus have the same kind of results. However we tried on other microscopes in particular a $400 \mathrm{kV}$ (Jeol 4000FX) to carry out EELS or X-ray analyses. We privileged first X-ray analyses with $200 \mathrm{kV}$ electron microscopes.

Following these first experiments in recording X-ray spectra from the region of the observed GP1 zone, we developed a simple geometric model to understand the role of the different parameters which can influence the measurements.

Ideal experimental configurations corresponding to the two orientations used and mean parameters are shown in figure 5 . An electron beam probe (Figs. $5 \mathrm{a}$ and $5 \mathrm{~b}$ ), $d_{\mathrm{B}}$ in diameter, focussed on to the GP1 zone excites an X-ray emission in a cylinder, as a first approximation (in fact the beam has a gaussian shape), going through the whole thickness $t$ of the foil. The mean copper concentration $C_{\mathrm{V}}$ in the volume of the cylinder which is measured by the $\mathrm{X}$-ray analyser, is expressed as:

$$
C_{\mathrm{V}}=C_{\mathrm{M}}+\left(C_{\mathrm{Z}}-C_{\mathrm{M}}\right) \frac{V_{\mathrm{Z}}}{V}
$$

where $C_{\mathbf{Z}}, C_{\mathrm{M}}$ are copper concentrations inside the GP1 zone and in the adjacent matrix respectively. $V_{Z}$ is the volume of the GP1 zone inside the cylinder of the beam (we don't take the slight spreading of the beam crossing the sample into account), and $V$ is the volume of the cylinder itself. $d_{\mathrm{Z}}$ and $t_{\mathrm{Z}}$ indicate the diameter and the thickness of the GP1 zone itself.

The ratio $V_{Z} / V$ depends on the diameter and position of the GP1 zone in the foil. If $d_{Z}<t$ (whole GP zone is inside the foil as shown in figure 5a; we don't consider half zones for instance), $V_{\mathrm{Z}}=d_{\mathrm{B}} d_{\mathrm{Z}} t_{\mathrm{Z}}$ and equation (1) becomes:

$$
C_{\mathrm{V}}=C_{\mathrm{M}}+\left(C_{\mathrm{Z}}-C_{\mathrm{M}}\right) \frac{4 d_{\mathrm{Z}} t_{\mathrm{Z}}}{\pi d_{\mathrm{B}} t}
$$




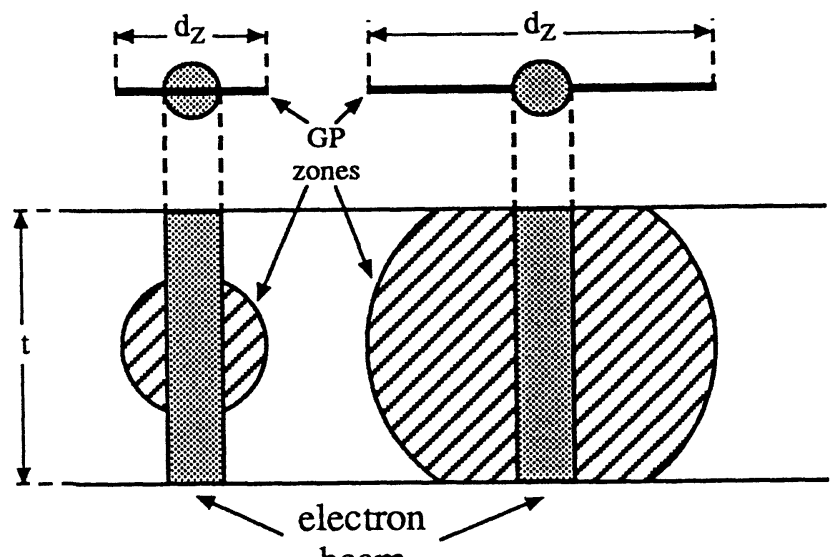

(a)

(b)

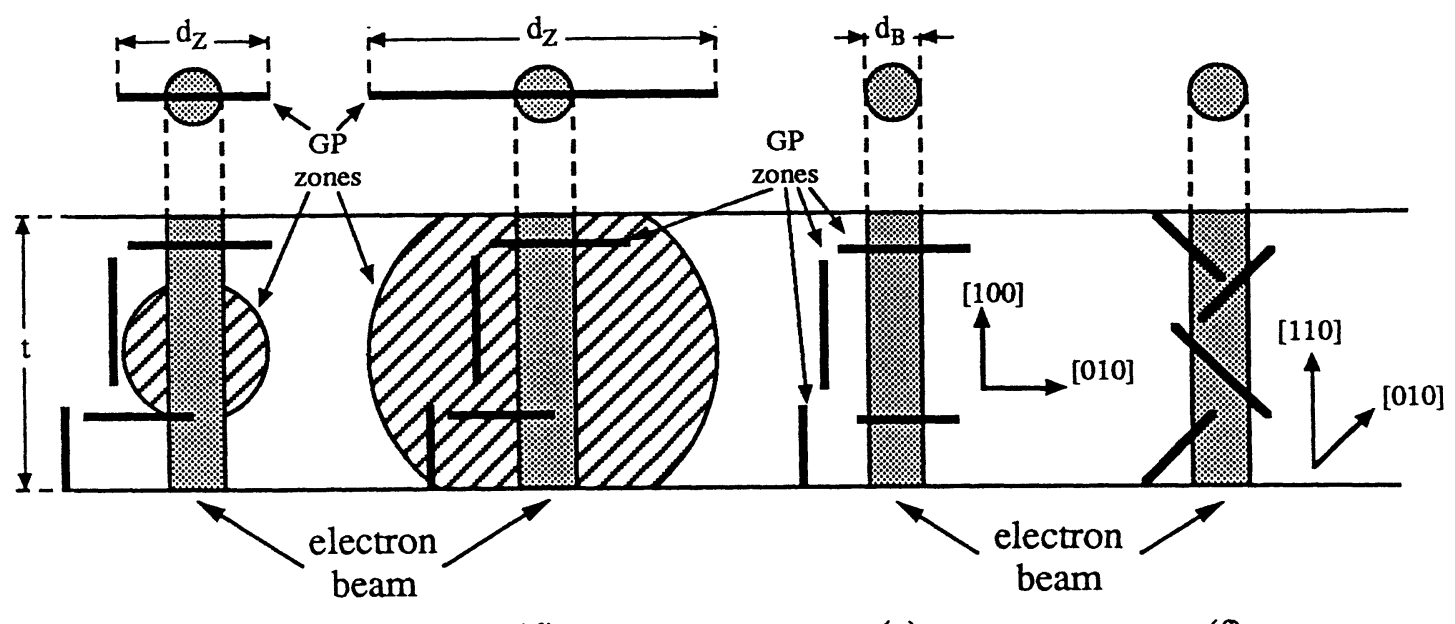

(c)

(d)

(e)

(f)

Fig. 5. - Experimental configurations which are considered for direct analysis of the Cu contents in the GP1 zones; the orientations are (100) [100] or (100) [110]. (a) $d_{Z}<t$, the zone inside the foil. (b) $d_{Z}>t$, the zone extends from the bottom to the top of the foil. However the real situation can be more complicated as, for instance, it is shown on $\mathrm{c}, \mathrm{d}$ or $\mathrm{e}$ and $\mathrm{f}$ for the probe on or out of a zone respectively.

If $d_{\mathrm{Z}}>t$ (GP zone goes from the top to the bottom through the whole thickness of the foil (Fig. 5b)), $V_{\mathrm{Z}}=d_{\mathrm{B}} t t_{\mathrm{Z}}$ and in these conditions we have

$$
C_{\mathrm{V}}=C_{\mathrm{M}}+\left(C_{\mathrm{Z}}-C_{\mathrm{M}}\right) \frac{4 t_{\mathrm{Z}}}{\pi d_{\mathrm{B}}}
$$

expression which does not depend on $t$. This situation is corresponding to the simplest situation as described in reference [2].

Using equations $(2,3)$ we can calculate and then plot all dependencies of $C_{\mathrm{V}}$ on the parameters mentioned above. 
In the case of high resolution imaging, the thickness of the foil can vary in the interval of 10$20 \mathrm{~nm}$, the thickness of the GP1 zone being constant and of the order of $0.2 \mathrm{~nm}$. The diameter (a circular shape is taken for simplification but has no real consequence here) of GP1 can vary (as observed from HREM images of the specimen annealed $100^{\circ} \mathrm{C} / 10 \mathrm{~h}$ ) from 5 to $25 \mathrm{~nm}$, the typical value being $10 \mathrm{~nm}$. As a beam diameter we can take the values from 1 (field emission) to $10 \mathrm{~nm}$.

The concentration of copper in the matrix $\left(C_{\mathrm{M}}\right)$ cannot be reliably measured because of the presence of GP1 zones in the $\{100\}$ planes parallel or tilted to the plane of the foil which are invisible (Figs. 5c, d, e, f). These zones cannot be neither avoided by the beam nor included to the contribution to measured signal because of their unknown number (volume).

But if we consider that the macroscopic concentration of the alloy $C_{\text {tot }}$ is 1.7 at.\%, the copper atoms being in the GP zones or uniformly spread in the matrix, an estimated value of $C_{M}$ can be obtained from the volume fraction of GP zones $F_{Z}$ in the volume of the sample, as a function of $C_{\mathbf{Z}}$ :

$$
C_{\mathrm{M}}=\frac{C_{\mathrm{tot}}-C_{\mathrm{Z}} F_{\mathrm{Z}}}{1-F_{\mathrm{Z}}}
$$

Considering that the zones are all monolayers (in reality it is only about $80 \%$ of them [11]) we estimated their volume fraction from TEM photographs assuming their density is equal under the three $\{100\}$ directions. We obtained $F_{Z}=0.98$ vol. $\%$ for the specimen aged $100^{\circ} \mathrm{C} / 10 \mathrm{~h}$. The plot of equation (4) for this value is shown in figure $6, C_{M}$ being 0.73 at. $\%$ for $C_{Z}=100$ at.\% Cu. If $C_{\mathbf{Z}}=50 \%, C_{\mathbf{M}}$ is 1.22 at $\%$.

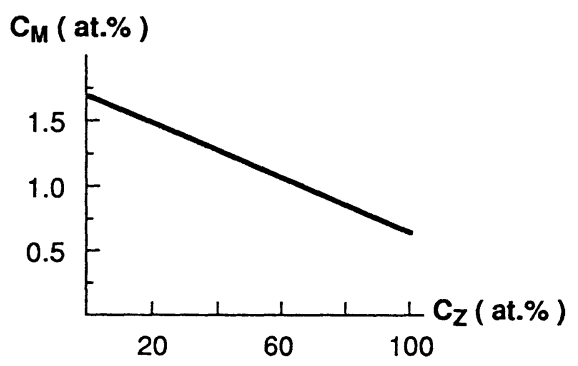

Fig. 6. - Copper content in the matrix as a function of concentration of copper atoms in the GP zones (plot of equation (4) for $C_{\mathrm{tot}}=1.7$ at.\% and $F_{\mathrm{Z}}=0.98$ vol.\%).

Figures 7 and 8 show plots of equation (2) as a function of different parameters. It is apparent that this value which is detected changes very sensitively with the beam diameter, the GP zone diameter and the thickness of the foil.

Plot of the equation (3) is shown in figure 9. Here the measured concentration depends only on the diameter of the electron beam probe.

A typical result we obtained in our preliminary measurements can be extracted from the last figure. The thickness of the sample was of the order of $20 \mathrm{~nm}$ and the beam diameter about $2 \mathrm{~nm}$. At $200 \mathrm{kV}$ the analyses with the Hitachi and the Philips FEG microscopes give $C_{\mathrm{V}} \sim 6.5$ at.\% on the zone and 5.4 at.\% out of the zone (see Ref. [10] for the kind of spectrum we obtained on a zone). 


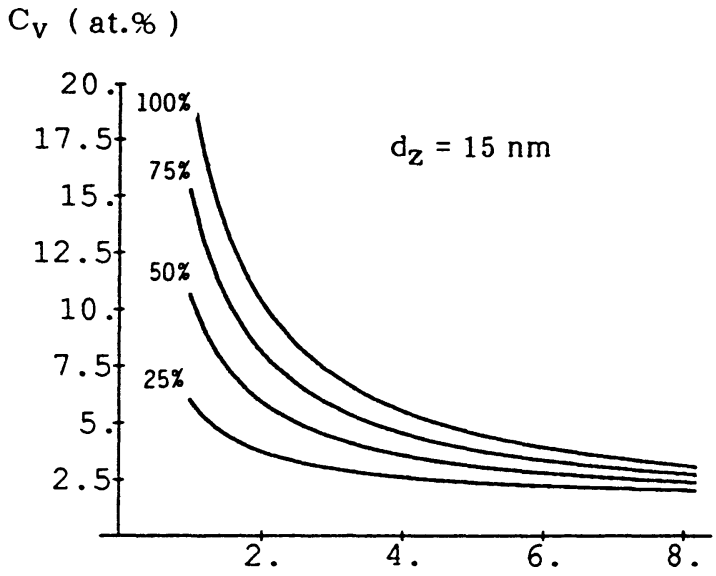

BEAM DIAMETER ( $\mathrm{nm})$
$\mathrm{C}_{\mathrm{V}}(\mathrm{at.} \%)$

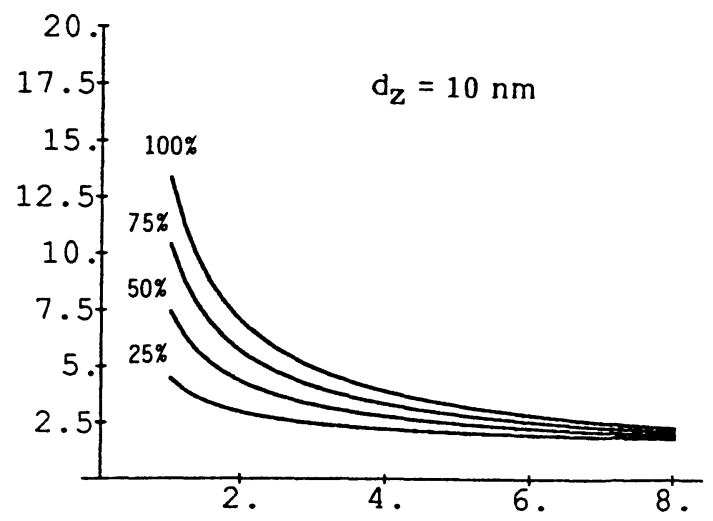

BEAM DIAMETER ( $\mathrm{nm})$

b)

Fig. 7. - Copper concentration $C_{\mathrm{V}}$ as measured by the $\mathrm{X}$-ray analyser as a function of beam diameter for different contents of $\mathrm{Cu}$ atoms in the GP zones, $d_{Z} \leq t$ (the whole GP zone is inside the foil); (a) $d_{\mathrm{Z}}=15 \mathrm{~nm}$, (b) $d_{\mathrm{Z}}=10 \mathrm{~nm}$. Foil thickness: $20 \mathrm{~nm}$.

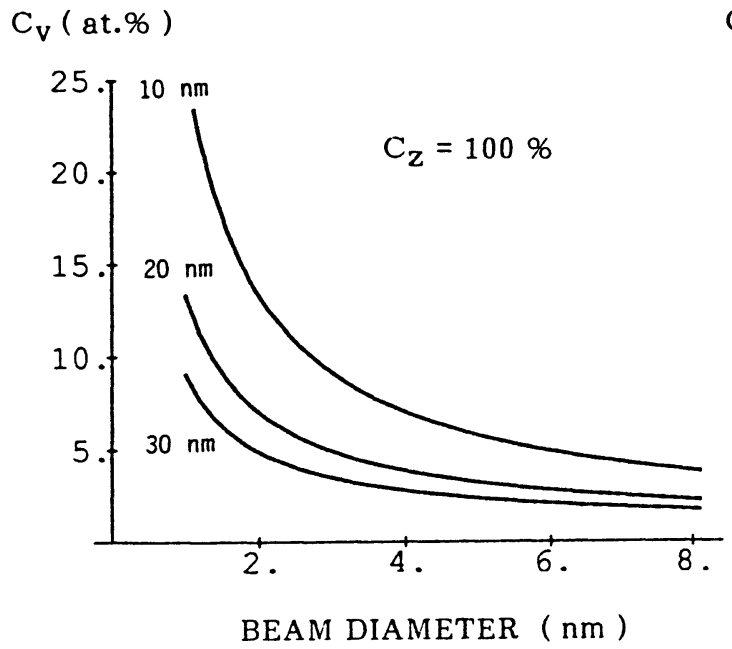

a)
$\mathrm{C}_{\mathrm{v}}($ at. $\%)$

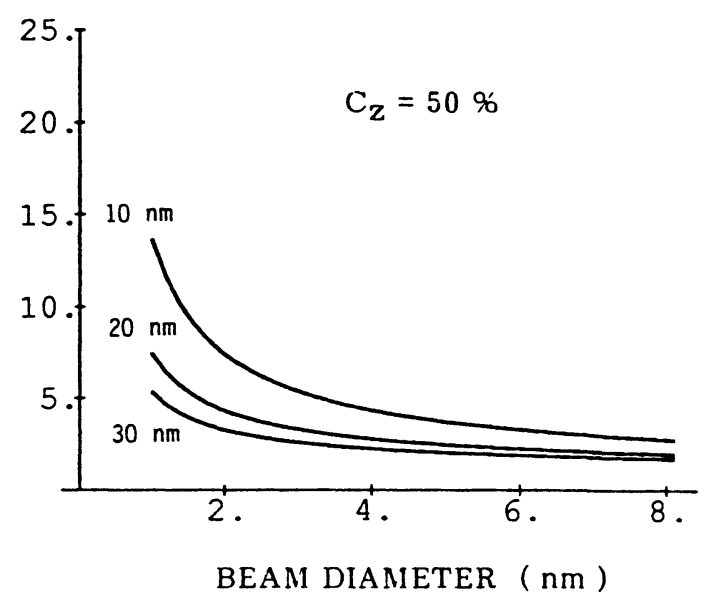

b)

Fig. 8. - Copper concentration $C_{\mathrm{V}}$ as measured by the $\mathrm{X}$-ray analyser as a function of beam diameter for different foil thicknesses, but with the condition $d_{\mathrm{Z}}<t$. (a) $C_{\mathrm{Z}}=100$ at.\%, (b) $C_{\mathrm{Z}}=50$ at.\%, diameter of the GP zone: $10 \mathrm{~nm}$.

Since the determination of the copper concentration out of the zone is $5.4 \%$ as determined experimentally, it is clear that either there are perpendicular zones to the beam which are not visible or a surface layer rich in copper due to redeposition during electropolishing. 


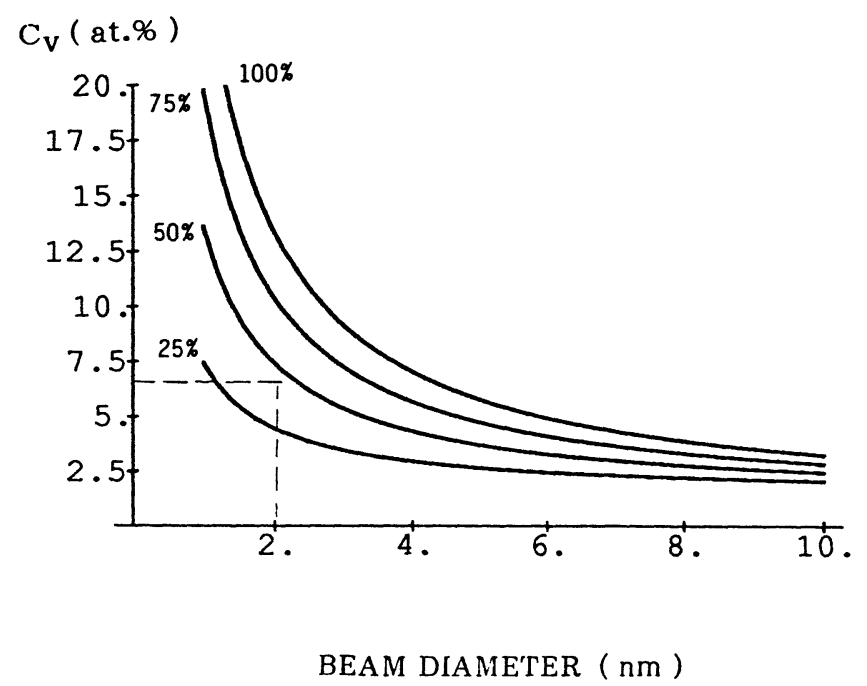

Fig. 9. - Copper concentration $C_{\mathrm{V}}$ a s measured by the $\mathrm{X}$-ray analyser as a function of beam diameter for different contents of $\mathrm{Cu}$ atoms in the GP zones according to equation (3). The GP zone crosses from the top to the bottom through the whole thickness of the foil $t\left[d_{\mathrm{Z}}>t\right.$ and $\left.t<20 \mathrm{~nm}\right]$. The concentration as measured for a probe diameter of $2 \mathrm{~nm}$ is $\mathrm{CV}_{\mathrm{V}}=6.5 \mathrm{at} \%$. Therefore it is clear from equation (3) or this figure that copper concentration in the zone is inferior to $50 \%$.

The equivalent thickness of copper, $t_{\mathrm{s}}$, due to this geometry is therefore given roughly by:

$$
t C_{\mathrm{M}}+t_{\mathrm{s}} C_{\mathrm{Z}}=\left(t_{\mathrm{F}}+t_{\mathrm{s}}\right) C_{\mathrm{V}}
$$

$t_{\mathrm{s}}$ can be guessed to be small. Therefore:

$$
C_{\mathrm{Z}} t_{\mathrm{s}} \sim t\left(C_{\mathrm{V}}-C_{\mathrm{M}}\right)
$$

If we consider that the situation is statistically the same on a zone we can introduce a supplementary term in the equation (2) or (3). The use of equation (3) gives a concentration slightly superior to $40 \%$. Using equation (5) would diminish this concentration which would become of the order of $30 \%$.

Therefore the copper concentration in the zone (the beam diameter is about $2 \mathrm{~nm}$ ) seems slightly inferior to $50 \%$ as obtained from equation (3) in the small number of cases we studied. Taking the real shape of the beam into account could give slightly different concentration depending on the precision of the centering of the probe on the GP zone and its stability in time. However a fundamental point must be addressed: what is the stability of GP1 zones under the beam during observation and analysis?

4.2 Deposited ENERGY AND RADiATION DAMAgE. - There is a fundamental question to be solved. We have to be sure that the structure of GP1 zones doesn't evolve under the beam. There are essentially two kinds of interactions, elastic and inelastic, which can deposit energy. We rapidly estimate the importance of both, to understand what is the most troublesome interaction to avoid in order to preserve the structure and the chemistry of the zone during analysis. 
As a first approximation, since thin films are concerned, the use of simple laws is sufficient. We use the notion of stopping power:

$$
\frac{\mathrm{d} E}{\mathrm{~d} t}=N \int_{0}^{2 k} T \mathrm{~d} \sigma
$$

where $N$ is the density of atoms per unit volume, $k$ the incident electron wave number, $t$ the thickness of the sample, $T$ the deposited energy corresponding to the differential cross-section $\mathrm{d} \sigma$.

Let us consider first the elastic stopping power corresponding essentially to the incident electronnucleus interaction calculated by means of the cross-section, $\mathrm{d} \sigma$, deduced from the Born approximation and the use of the Yukawa-Wentzel potential.

Since the alloy is essentially composed of aluminium, we write $T$ as:

$$
T=\frac{\hbar^{2} q^{2}}{2 m_{\mathrm{Al}}}
$$

$\mathbf{q}$ is the momentum change of the incident electron due to the elastic interaction between this electron and an atom with a mass $m_{\mathrm{Al}}$.

The stopping power has therefore the expression [12]:

$$
\left(\frac{\mathrm{d} E}{\mathrm{~d} t}\right)_{\text {nucl }}=N 4 \pi \hbar^{2} a^{4}\left(\frac{\gamma}{a_{0}}\right)^{2} \frac{Z^{2}}{k^{2}} \frac{1}{m_{\mathrm{Al}}} \int_{0}^{2 k} \frac{q^{3}}{\left(1+a^{2} q^{2}\right)^{2}} \mathrm{~d} q
$$

where $\gamma$ is the relativistic parameter and $Z$ the atomic number. The integration gives:

$$
\left(\frac{\mathrm{d} E}{\mathrm{~d} t}\right)_{\mathrm{nucl}}=N 2 \pi\left(\frac{\gamma}{a_{0}}\right)^{2} \frac{Z^{2}}{k^{2}} \frac{\hbar^{2}}{m_{\mathrm{Al}}}\left[\operatorname{Ln}\left(4 k^{2} a^{2}\right)-1\right]
$$

For aluminium, the Fermi screen parameter is expressed as:

$$
a=0.889 a_{0} Z^{-1 / 3}=0.0192 \mathrm{~nm}
$$

$a_{0}$ being the Bohr radius.

The elastic stopping power is therefore about $1100 \mathrm{eV}$ per $\mathrm{cm}$ for $200 \mathrm{keV}$ electrons, and $850 \mathrm{eV}$ per $\mathrm{cm}$ for $400 \mathrm{keV}$ electrons.

On the other hand, the stopping power related to inelastic interactions (electron-electron interactions) is given by the expression:

$$
\left(\frac{\mathrm{d} E}{\mathrm{~d} t}\right)_{\mathrm{e}^{-}} \approx \frac{2 \pi N e^{4} Z m}{\hbar^{2} k^{2}}\left[\operatorname{Ln}\left(\frac{2 E_{\mathrm{c}}^{2}}{\frac{\overline{\Delta E}_{\mathrm{i}}^{2}}{2}}\right)+1\right]
$$

where $m$ is the mass of the electron, $E_{\mathrm{c}}$ the electron incident energy and $\overline{\Delta E}_{\mathrm{i}}$ the mean ionization energy. The more precise relativistic expression is [13]:

$$
\begin{aligned}
\left(\frac{\mathrm{d} E}{\mathrm{~d} t}\right)_{\mathrm{e}^{-}}= & \frac{2 \pi N \mathrm{e}^{4} Z}{m v^{2}}\left[\operatorname{Ln}\left(\frac{(\gamma-1)\left(\gamma^{2}-1\right) m^{2} c^{4}}{\overline{\Delta E}_{\mathrm{i}}^{2}}\right) \ldots\right. \\
& \left.-\left(1+\frac{2 \gamma-1}{\gamma^{2}}\right) \operatorname{Ln} 2+\frac{1}{\gamma^{2}}+\frac{1}{8} \frac{(\gamma-1)^{2}}{\gamma^{2}}\right]
\end{aligned}
$$


$\overline{\Delta E}_{\mathrm{i}}$ is estimated from the Berger and Seltzer expression [12]. It is of the order of $163 \mathrm{eV}$ for aluminium. The average energy deposited to the sample is essentially due to electron-electron interactions as it is well-known. Using expressions (7) and (8), we have:

$$
\frac{\left(\frac{\mathrm{d} E}{\mathrm{~d} t}\right)_{\text {nucl }}}{\left(\frac{\mathrm{d} E}{\mathrm{~d} t}\right)_{\mathrm{e}^{-}}} \approx \frac{Z m}{m_{\mathrm{Al}}} \approx 3 \times 10^{-4}
$$

The inelastic average energy deposited to the sample is, in the case of aluminium and $200 \mathrm{keV}$ electrons of the order of $5.9 \mathrm{MeV}$ per $\mathrm{cm}$ and per incident electron. This value is obtained from the relativistic expression for the stopping power.

Since we are concerned with a very thin film, a simple approximation to estimate the deposition of energy can be used. The relation between the stopping power and the absorption exponential scattering law enables the linear inelastic absorption coefficient to be expressed as:

$$
\mu=\alpha_{\mathrm{ab}} \rho=\frac{P_{\mathrm{dep}}}{P_{0} t}=\frac{(\mathrm{d} E / \mathrm{d} t) \cdot t \cdot n}{P_{0} t}=\frac{(\mathrm{d} E / \mathrm{d} t) \cdot t \cdot n}{\phi_{\mathrm{acc}} n e}=\frac{\mathrm{d} E / \mathrm{d} t}{\phi_{\mathrm{acc}} e}
$$

where $\rho$ is the density of the material, $\alpha_{\mathrm{ab}}$ the ratio $\mu / \rho, n$ the number of electrons passing per second in the cylinder defined by the probe and $\phi_{\text {acc }}$ the accelerating voltage. $P_{0}$ is the power of the incident beam. Take as an example $200 \mathrm{keV}$ electrons. If we consider that the current in a probe of $3 \mathrm{~nm}$ in diameter is about $5 \times 10^{-9} \mathrm{~A}$, the corresponding power is $10^{-3}$ Watt.

$$
P_{\mathrm{dep}}=\mu P_{0} t \text { or } P_{\mathrm{dep}}=\frac{\mathrm{d} E / \mathrm{d} t}{\phi_{\mathrm{acc}} e} P_{0} t
$$

The number of electrons passing through the small cylinder is about $2.5 \times 10^{10}$ per second. Therefore the deposited power in a thin layer, say $20 \mathrm{~nm}$ thick, is about $2.6 \times 10^{-8}$ Watt. The use of the formula proposed by Castaing [14] for thin films can give an estimation of the maximum temperature, $\theta_{\mathrm{m}}$, of the sample at the level of the probe.

$$
\theta_{\mathrm{m}}=\frac{P_{\mathrm{dep}}}{4 \pi K t}\left(1+2 \operatorname{Ln} \frac{R}{r_{\mathrm{p}}}\right)
$$

where $P_{\text {dep }}$ is the power deposited to the sample, $K$ the thermal conductivity, $R$ the distance from the center where the sample is at the room temperature, and $r_{\mathrm{p}}$ the radius of the probe.

The corresponding increase of temperature can be of the order of a part of degree as a maximum if taking $K$ as $\sim 250$ Watt. $\mathrm{m}^{-1} . \mathrm{K}^{-1}$. If the current is ten times higher the temperature will be of the order of a few degrees. Therefore, it does not appear that, for very thin samples as used for high resolution, the rise of temperature is important, as long as the sample is well tightened to the specimen holder. The major disturbance related to the deposited energy is the possible creation of point defects.

The average elastic stopping power energy includes this creation. However, we have to estimate the maximum energy which can be transferred to the atoms of the sample. Aluminium atoms can receive energy directly from incident electrons or indirectly through a collision electron $\rightarrow$ copper atom $\rightarrow$ aluminium atom. We don't know exactly what is the energy threshold displacing copper atoms in a matrix of aluminium and more precisely in a GP zone. Anyway, the most important and probable deposition of energy to the nucleus will be through a direct processus to aluminium. 
The direct deposition of energy to a single atom is given by:

$$
T=4 \frac{m}{m_{1}} E_{\mathrm{c}}\left(1+\frac{E_{\mathrm{c}}}{2 m c^{2}}\right) \sin ^{2} \theta / 2
$$

where the maximum $T_{\mathrm{m}}$ is obtained for $\theta$, the electron scattering angle, equal to $\pi, m_{1}$ the mass of the atom.

$$
T_{\mathrm{m}}=4 \frac{m}{m_{1}} E_{\mathrm{c}}\left(1+\frac{E_{\mathrm{c}}}{2 m c^{2}}\right)
$$

An indirect deposition of energy is possible since there are two kinds of atoms, $m_{1}$ and $m_{2}$, in the alloy. The maximum deposited energy, through this process, is given by:

$$
T_{\mathrm{m}}=16 \frac{m m_{2}}{\left(m_{1}+m_{2}\right)^{2}}\left[1+\frac{E_{\mathrm{c}}}{2 m c^{2}}\right] E_{\mathbf{c}}
$$

The expression for a direct transfer of energy to the matrix atoms is found again by replacing $m_{2}$ by $m_{1}$, the mass of the major element.

Values given by expressions (14) and (15), i.e. through a direct or indirect processus, are shown in table I.

Table I. - Calculated values of deposited energy through direct or indirect processus. The direct knock-on $\left(\mathrm{e}^{-} \rightarrow \mathrm{Al}\right)$ is the most damaging processus above the threshold energy.

Deposited Energy (eV)

\begin{tabular}{|c|c|c|c|c|}
\hline $\mathrm{keV}$ & $\mathrm{e}^{-} \rightarrow \mathrm{Cu}$ & $\mathrm{e}^{-} \rightarrow \mathrm{Al}$ & $\mathrm{e}^{-} \rightarrow \mathrm{Cu} \rightarrow \mathrm{Al}$ & $\mathrm{e}^{-} \rightarrow \mathrm{Al} \rightarrow \mathrm{Cu}$ \\
\hline 100 & 3.79 & 8.93 & 3.17 & 7.47 \\
200 & 8.26 & 19.45 & 6.91 & 16.28 \\
300 & 13.40 & 31.56 & 11.22 & 26.41 \\
400 & 19.22 & 45.26 & 16.09 & 37.88 \\
1000 & 68.34 & 160.91 & 57.19 & 134.67 \\
\hline
\end{tabular}

The threshold by direct knock-on for an atom of aluminium embedded in a matrix of the same kind of atoms is of the order of $150 \mathrm{keV}$ [15] for an atom recoil energy of $14 \mathrm{eV}$. Other determinations give a necessary recoil energy of $16 \mathrm{eV}$ or threshold electron energy of about $170 \mathrm{keV}$. We notice that, for a $200 \mathrm{keV}$ incident electron, the maximum recoil energy given to $\mathrm{Cu}$ through a primary knock-on to $\mathrm{Al}$ atoms is at the limit of the necessary energy to displace a $\mathrm{Cu}$ atom if we consider that $\mathrm{Cu}$ atoms need an energy of the order of $16 \mathrm{eV}$ to be displaced as well, what is not really clear. Consequently only direct knock-on process to $\mathrm{Al}$ atoms and subsequent atomic diffusion seem to be important, which is not surprising since the copper mass is largely superior to the aluminium one. It would be different, if the minority atom was lighter than $\mathrm{Al}$ (for instance in Al-Li alloys). As it is seen from table I, the use of 300 or $400 \mathrm{keV}$ electrons clearly creates point defects (Frenkel pairs).

The probability of these events and therefore the elastic cross-section corresponding to the formation of defects to determine the number of displacements per second and per atom must 
then be calculated. The exact expression of the cross-section corresponding to the creation of a point defect is difficult to be calculated. However there is an approximate expression due to McKinley and Feshbach [16]:

$$
\begin{aligned}
\sigma_{\mathrm{d}}= & 2.48 \times 10^{-25} Z^{2}\left(\frac{1-\beta^{2}}{\beta^{4}}\right) \frac{T_{\mathrm{m}}}{T_{\mathrm{d}}}\left\{1+2 \pi \alpha_{\mathrm{z}} \beta\left(\frac{T_{\mathrm{m}}}{T_{\mathrm{d}}}\right)^{1 / 2} \ldots\right. \\
& \left.-\frac{T_{\mathrm{m}}}{T_{\mathrm{d}}}\left[1+2 \pi \alpha_{\mathrm{z}} \beta+\left(\beta^{2}+\pi \alpha_{\mathrm{z}} \beta\right) \operatorname{Ln} \frac{T_{\max }}{T_{\mathrm{d}}}\right]\right\}
\end{aligned}
$$

where $Z$ is the atomic number, $\alpha_{\mathrm{z}}=Z / 137, \beta=v / c$, and $T_{\mathrm{d}}$ the displacement energy (threshold). Here, in the case of aluminium, this displacement energy has been determined [12] as $16 \mathrm{eV}$. It is the necessary mean energy to be given to an atom create a vacancy-interstitial pair in the bulk. The presence of copper doesn't significantly change this value. The cross-section is found to be of the order of 10 barns at $200 \mathrm{keV}$, and a little more than 30 barns at $400 \mathrm{keV}$. If we use a probe of $3 \mathrm{~nm}$ in diameter and a current equal to $5 \times 10^{-9} \mathrm{~A}$, the flux, $\phi_{0}$, is of the order of $4.4 \times 10^{23} \mathrm{e} / \mathrm{cm}^{2} . \mathrm{s}$ and the number of displacements is roughly given by $\sigma_{\mathrm{d}} \phi_{0}=10 \times 10^{-24} \times 4.4 \times 10^{23} \cong 4$ displacements per atom and per second. This value becomes of the order of 12 at $400 \mathrm{keV}$. These values are rather important and can strongly affect the structure of GP zones when performing point analysis of the material. For a high resolution situation corresponding to an area of about $150 \mathrm{~nm} \times 150 \mathrm{~nm}$ at a magnification between $500000 \mathrm{X}$ and $1000000 \mathrm{X}$, and a current of the order of $5 \times 10^{-8} \mathrm{~A}$ or $3 \times 10^{11} \mathrm{e} / \mathrm{s}$, it is found that the flux is of the order of $10^{21} \mathrm{e} / \mathrm{cm}^{2} / \mathrm{s}$ about. Therefore the frequency of atom displacements at $200 \mathrm{keV}$ with FEG is of the order of 0.01 per atom per second. For an exposure of a few seconds on a fresh area, this number is reasonable. It will be also acceptable at $400 \mathrm{keV}$. The situation is therefore much more delicate for analysis.

It is clear, through this simple estimation, that in our case the energy of incident electrons has to be smaller (but as close as possible) than the threshold energy of the creation of defects, to avoid any beam ind uced change in the structure of GP zones. In addition, as already mentioned, it is difficult to say anything very precise about the threshold concerning the $\mathrm{Cu}$ atoms embedded in the aluminium matrix. It is therefore recommended to use an electron microscope working below the threshold, say $160 \mathrm{keV}$. However atomic resolution is needed to be able to detect the monolayers unambiguously. A recent test, carried out at $160 \mathrm{kV}$, has shown that with a FEG Philips CM 20 Supertwin the experiment is possible. We succeeded with Coene and Otten to observe GP1 zones in a (100) [100] orientation. The resolution was clearly better than $0.2 \mathrm{~nm}$. Therefore at the level of $0.18-0.2 \mathrm{~nm}$ resolution or even better, it is possible to perform sub-threshold electron microscopy what will be quite useful to the future.

\section{Conclusion.}

GP zones can be easily observed with HREM microscopes operated either at 400 or $200 \mathrm{kV}$. In particular the new $200 \mathrm{kV}$ Hitachi and Philips microscopes, equipped with field emission guns, offer the possibility of visualizing them with a high contrast. With these microscopes, elemental analysis is also possible even if the geometry and the density of the zones make this experiment delicate. We have obtained preliminary results. They show that, at least for the small number of analysed zones, the concentration of copper in GP1 zones is not $100 \%$, but closer to $50 \%$ or less. It is clear that other experiments have to be carried out to provide more accurate data. It has been shown that it is quite possible to carry out sub-threshold electron microscopy and to observe in this condition monolayer GP1 zones. Therefore it is recommended to perform experiments below $160 \mathrm{kV}$ to avoid any damage which can modify the results of the point analysis. 
It is interesting to see that this subject which was opened independently by the pioneering work of Guinier and Preston more than 50 years ago and, in transmission electron microscopy, in particular by Castaing in the early fifties, has remained of high interest due to the improvement of the techniques in high resolution and analytical microscopy.

\section{Acknowledgements.}

We are indebted to many colleagues from different laboratories: Drs A. Bourret and J. Thibault (CENG), Dr D. Imhoff (CNRS-Meudon-Bellevue), Dr G. Hug (CNRS-ONERA), Dr Y. Ueki (Hitachi Naka Works) and Drs W. Coene and M. Otten (Philips Eindhoven). One of the authors, M. Karlík, thanks the French Government for a grant.

\section{References}

[1] AshBY M.F. and BRown L.M., Philos. Mag. 8 (1963) 1649.

[2] JOUFFREY B. and DORIGNAC D., J. Phys. I France 2 (1992) 1067.

[3] CASTAING R. et Guinier A., C.R. Acad. Sci. 228 (1949) 2033.

[4] CASTAing R. et LabORIE P., C.R. Acad. Sci. 237 (1954) 1330.

[5] PRESTON G.D., Philos. Mag. 26 (1938) 855.

[6] Guinier A., Ann. Phys. 13 (1939) 161.

[7] JoufFreY B., DORIGNAC D. and BourRet A., Proceed. XIIth Intern. Cong. for Elect. Microsc. (San Francisco Press) 1 (1990) 14.

[8] Casanove M.J., DorignaC D. and Jouffrey B., EMAG Inst. Phys. Conf. 61 Chapt. 8 (1981) 377.

[9] IsaKoZaWA S., KaShikURa Y., Sato Y., TAKahashi T., ICHIHASHI M., MURAKOSHI H., Microsc. Microanal. Microstruct. 1 (1990) 159.

[10] OTtEN M.T., MUL P.M. and de Jong M.J.C., Microsc. Microanal Microstruct. 3 (1990) 83.

[11] SATO T. and TAKAHASHI T., Script. Met. 22 (1988) 959.

[12] JouffreY B., in Microscopie Electronique en Science des Matériaux, B. Jouffrey, A. Bourret, C. Colliex Eds.) (Ed. du CNRS, 1983) p. 85.

[13] Perez J. Ph., Thesis, Toulouse (1975).

[14] Castaing R., Thesis, Paris (1951).

[15] URBAN K., in Microscopie Electronique à Haute Tension, 1975, B. Jouffrey et P. Favard Eds. (SFME, 1976) p. 159.

[16] MCKinley W.A. and Feshbach H., Phys. Rev. 74 (1948) 12. 